\title{
Restructuring as gratification
}

\author{
Jeffrey Braithwaite ${ }^{1}$ Johanna Westbrook ${ }^{2}$ Rick ledema ${ }^{3}$
}

$J$ J Soc Med 2005;98:542-544

\section{INTRODUCTION}

Almost everyone does it. It is pleasurable for some, apparently, and stressful for others-you only have to watch people at it. Others find it painful. A relatively small number is opposed to it, and will fight hard to stop it happening. But they are few, and most people simply grin and bear it.

Restructuring is so pervasive, in fact, that observers could be forgiven for thinking it is the only change tool available. In the health sectors of Britain, New Zealand, Canada, the USA and Australia the activity seems virtually continuous. Primarily it consists of regular mergers, altering the responsibilities between central and peripheral bodies, setting up new agencies that trigger domino-like changes to the official responsibilities of other agencies, constantly tweaking organizational charts and re-orienting who reports to whom.

\section{THE EVIDENCE}

The evidence for this making a difference, let alone demonstrably improving productivity or outcomes, is surprisingly slender. This is the case for both system-wide and organizational-level restructuring. After a landmark OECD (Organization for Economic Co-operation and Development) study lasting 3 years, the report's authors could only conclude 'structural reform to health systems and the organisation of delivery and management systems hold promise'. ${ }^{1}$

In truth, there are no randomized trials, no longitudinal studies of multiple restructuring events or time series designs and little scientifically acceptable cross-sectional work. There are local case-study examples in the grey literature, of course, but hypothesis-testing research is virtually non-existent. Where there are studies, they challenge rather than support restructuring (Box 1).

Anecdotally, one hears the groans of clinicians when the next restructure is proposed or new body announced.

${ }^{1}$ Associate Professor, Director, Centre for Clinical Governance Research, ${ }^{2}$ Associate Professor, Deputy Director, Centre for Health Informatics, ${ }^{3}$ Senior Lecturer, Deputy Director, Centre for Clinical Governance Research, Faculty of Medicine, University of New South Wales, Sydney NSW 2052, Australia
Box 1 Evidence challenging the restructuring phenomenon

- Between 1999 and 2003 there were 2497 mergers and acquisitions in the healthcare industry of the USA, yet the latest evidence suggests that mergers induce less competition and lead to increases in prices of some $53 \%$ (Ref. 15)

- A study of 20 teaching hospitals restructuring their clinical directorates in New South Wales and Victoria, the two largest Australian States, showed that efficiency gains sought were not realized, and that one structural type was as efficient as any other (Ref. 17)

- Case study research into 25 National Health Service trusts merged between 1996 and 2001 revealed that, although mergers can realize some benefits, there were considerable negative effects including: setbacks of at least 18 months in progress; problems in fusing different organizational cultures; no better recruitment and retention of clinical staff; and savings below those forecasted (Refs 18,19)

- New Zealand restructured its health services in the 1990s along quasi-market, competitive lines including a purchaser-provider split, and has now turned $180^{\circ}$, re-instituting a public sector model (Ref. 20)

Usually management consultants or government advisors are the proselytizers. Many bedside clinicians look up into the far reaches of hospital structures and see that, although new organizational charts are released displaying new boxes with novel titles and some trimming of old positions, not a lot changes in terms of their own work or responsibilities. Sure, the title of their clinical directorate may alter because someone fuses two or more together - or the name of a new national body is publicized with fanfare, with a mandate to enhance quality or safety or compliance with regulations - but the professional arrangements that deliver direct, local care to patients seem untouched.

All too often, regardless of good intentions, restructuring is merely thinly-disguised public relations, and spun as strategic, creative change for the better. Those in authority, notably ministers for health, move to change the organizational chart, install a new agency, or re-order some people's responsibilities at the apex of the health system, and propose that reform has been accomplisheduntil the next structural 'transformation' is identified. Sometimes the motive is to configure like services with like more snugly to achieve 'strategic fit'. But often the purpose is political, with intended outcomes ranging from ridding the system of dead wood to 'demonstrating' something 


\section{Box 2 Recent voices on restructuring}

- 'Reorganizations remain a clumsy reform tool that tend to produce a drop in performance. It takes a new organization at least 2-3 years to start to perform as well as its predecessor"*

- 'There has always been a tendency for both Governments and opposition parties to believe that the secret to improving patient care is restructuring the National Health Service. This means that the NHS has been in an almost constant state of reform since its inception, when what is needed is a period of relative stability"

- 'It is a constant strain on the NHS that they never let organizations establish themselves before they reorganize them'

- 'Many healthcare change initiatives in the past have introduced large-scale structural reforms. While structural reforms are important and necessary, they have not always delivered their intended impact, with services for staff and patients often only changing a little"s

- 'The Government's ambitious programme of structural reorganization has brought with it an increasingly fragmented health service'.

*Niall Dickson, Chief Executive King's Fund. In: Lloyd I. Commissions mergers could cause 'turmoil'. Health Serv J 24 March 2005;115:6

Nigel Edwards, Director of Policy, NHS Confederation. In: NHS Confederation. New Proposals For Restructuring The NHS Will Not Help Improve Patient Care, Press

Release 13 January 2005. [www.nhsconfed.org/press/releases/new_proposals_for restructuring_the_nhs_will_not_help_improve_patient_care.asp] accessed 9 October 2005

"Naomi Fulop, Senior Lecturer, London School of Hygiene and Tropical Medicine. In: Lloyd I. Commissions mergers could cause 'turmoil'. Health Serv J 24 March 2005; 115:6

'National Health Service. Improvement leaders' guide to building and nurturing an improvement culture. Leicester: NHS Modernisation Agency, 2004:9

"The NHS: a national health sham. Lancet, 2005;366:1239

significant is being done, all in the absence of tackling complex systems problems. Box 2 resonates with aphoristic voices about restructuring.

Those who seek to change the structure are taking a formal view of organizing. Organizations are being thought of in hierarchical, mechanistic and bureaucratic terms. Proponents are in essence asserting that structural alterations will lead to profound change rather than merely altering the boxes on the organizational chart. Organizational theorists think that such restructuring-as-tinkering rarely modifies the operating assumptions, norms and behaviour of participants, and when it does, the shifts are marginal. 2,3 Thus clinical practices and networks are relatively unaffected, and even when they are, it may well be that the forces that regress change back to the organizational mean, and thus restore the status quo, are powerful. Some social scientists believe it is much more productive to work on changing the cultures than the structures of the system. This of course is a long (not short)-term endeavour, and it is much harder. ${ }^{4}$ Patterns of influence and power, and cultural practices, are distributed in human systems in complex ways, are more deep-seated than restructuring advocates acknowledge, and are resistant to change, sometimes strongly so.

Despite this, the conclusion reached by many restructurers in positions of authority is: let us keep doing what we know. Why? Because they imagine that this is viable change, or pretend it is. To the casual observer it seems there is a restructuring industry, so prevalent is the activity, and those providing bedside and community care are being ignored. ${ }^{5}$

\section{A RESEARCH APPROACH?}

It does seem time to develop sound, clearly conceptualized research designs to study structural effects. We might scientifically examine say large hospital restructuring, the on-the-ground contributions of new national bodies to changing clinical work or the international experience on the relative benefits of centralizing or decentralizing services. We might try to correlate restructuring with improved patient outcomes, for instance. Is there a causal relationship? On the argument we take here, it will be likely found that restructuring has failed in many instances to penetrate the system sufficiently to change practices, or fundamental culture, or patient care, to any degree. The Institute of Medicine in the USA has argued this point in its landmark publication Crossing The Quality Chasm: 'In general, structural measures have not been consistently shown to relate either to process quality or outcomes' ${ }^{6}$

Consider the support for this proposition from recent international experience. We do not have to search far to find examples. In the period 1995 to now restructurers have been busy at work in all eight Australian states and territories. Amongst much minor tinkering, each has conducted a major reorganization at least once, and twice in the case of Western Australia, South Australia, Australian Capital Territory, Victoria and Tasmania. The main trend is a shift toward centralized control of services, although commentators think this might be a temporary state of affairs, and decentralization may come into vogue..$^{7,8}$ The only clear point in all this is that it is unclear if the effects have been beneficial or deleterious to patient care.

In another Federated system, that of Canada, Saskatchewan and Alberta regionalized their health systems in the first half of the 1990s, and appointed Boards to run them, while Ontario stood apart from this. ${ }^{9,10}$ The 33 Saskatchewan districts created in 1993 were reduced to 13 in 2002; Alberta redrew its regional boundaries from 17 in 1994 to nine and a cancer board in 2003; and Ontario consistently rejected regionalization across time. The Province of Prince Edward Island regionalized in 1993, restructured in 2002 and abruptly disbanded this structure in 2005. Saskatchewan and Alberta conspicuously flirted with differing mixes of politically-appointed or elected Boards in this period, as did Quebec. No one has quantified the extent to which these changes have resulted in positive effects, more uncertainty, or destabilization. 
Meanwhile in the USA of the 1990s, managed care arrived. This was a strategy of private sector structural change to achieve profit enhancement, ushered in when President Bill Clinton's proposal ${ }^{11}$ to regulate care for all failed. ${ }^{12}$ Managed care induced, or failed to arrest, accelerating cost-inflation pressures once one-off inefficiencies were squeezed out. Now, the system needs to be reformed. According to the taste of the commentator concerned reform should sit somewhere between the rock of 'socialized medicine', which is what American opponents call a universal not-for-profit insurance system, and the hard place of 'marketplace medicine', where private enterprise and competition rule. Wholesale structural measures such as managed care and mergers and acquisitions amongst private healthcare chains have not solved the problems of the USA healthcare system in the past. ${ }^{13}$ How can they now?

What if managers, policymakers and ministers took the null hypothesis, and simply put an embargo on all forms of restructuring on the basis of the proposition that it might be futile? Imagine the resources that would become available. We could re-allocate the investments to direct patient care, or to researching how to do culture change better. Interestingly, according to a King's Fund's report ${ }^{14}$ the Blair Government's increased National Health Service spending, in the order of $£ 30$ billion since 1997-1998, appears to have arrested consistently rising waiting lists. This underscores the point: funding injections affected the trend, not the many historical NHS restructures. It may be little more than a pipe dream - considering how frequently restructuring occurs and how ubiquitous is the formal view of organizing - but encouraging people to shift the mindset to one which forced proponents to measure the benefits resulting from structural change might be no bad thing.

\section{DOING IT FOR PLEASURE}

In doing so we might thereby assemble an evidence-base to inform how and under what circumstances we should do it, and how to make it more effective, or even pleasurable, for all concerned. Perhaps then those participating, the voyeurs watching on or those simply theorizing about its benefits might report improved levels of satisfaction. At the very least, those who experience it as pain might have the worst of their discomfort alleviated.

Logic suggests if very well informed about its dangers, or convinced it is more trouble than it is worth, people will stop doing it as often, with some even practising abstinence. Because unlike sex, restructuring is not essential for the propagation of humankind.

\section{REFERENCES}

1 OECD. The OECD Health Project: Toward High Performing Health Systems. Paris: OECD, 2004

2 Alvesson M. Understanding Organizational Culture. London: Sage, 2002

3 Schein E. Organizational Culture and Leadership, 3rd edn. San Francisco: Jossey-Bass, 2004

4 Braithwaite J, Westbrook M, Iedema R, Mallock N, Forsyth R, Zhang K. A tale of two hospitals: clinical service structures as an expression of different organisational cultures. Soc Sci Med 2005;60:1149-62

5 Jeffcoate W. Care and despair in the UK National Health Service. Lancet 2005;366:694-5

6 Institute of Medicine. Crossing the quality chasm: a new health system for the 21st century. Washington: National Academy Press, 2001

7 Dwyer J. Australian health system restructuring - what problem is being solved? Aust NZ Health Policy 2004;1 :doi: 10.1186/1743-3462-1-6

8 Rix M, Owen A, Eager K. (Re)form with substance? Restructuring and governance in the Australian health system 2004/05. Aust NZ Health Policy 2005;2:doi: 10.1186/1743-8462-2-19

9 Levine D. Regionalisation: an opportunity for improving management. Healthcare Papers 2004;5:46-54

10 Lewis S, Kouri D. Regionalisation: making sense of the Canadian experience. Healthcare Papers 2004;5:12-30

11 Clinton WJ. Health Security: The President's Health Care Plan. Washington DC: US Government Printing Office, 1993

12 Braithwaite J. Health care reform under President Clinton: issues, ideas and implications. Aust J Public Admin 1995;54:102-12

13 Relman AS. Restructuring the US health care system. Issues in Science and Technology Online 2005;Summer(2003):http://www.issues.org/

14 King's Fund. An independent audit of the NHS under Labour (1997-2005). London: King's Fund Publications, 2005

15 Gaynor M, Vogt W. Competition among hospitals. RAND J Economics 2003;34:764-85

16 Irving Levin Associates. The Health Care Acquisition Report, 10th edn. Canaan, CT: Irving Levin Associates, 2004

17 Braithwaite J, Westbrook M, Hindle D, Iedema R, Black D. Does restructuring hospitals result in greater efficiency? An empirical test using diachronic data. Health Services Management Res, in press

18 Fulop N, Protopsaltis G, Hutchings A, et al. Process and impact of mergers of NHS trusts: multicentre case study and management cost analysis. BMJ 2002;325:246-9

19 Fulop N, Protopsaltis G, King A, Allen P, Hutchings A, Normand C. Changing organisations: a study of the context and processes of mergers of health care providers in England. Soc Sci Med 2005;60: 119-30

20 Devlin N, Maynard A, Mays N. New Zealand's health sector reforms: back to the future? BMJ 2001;322:1171-4 